\title{
Acute Physiology and Chronic Health Evaluation (APACHE) II Pada Angka Kematian Pasien Gagal Nafas
}

\author{
Bambang Suryadi ${ }^{1}$, Nurul Ainul Shifa ${ }^{2}$ \\ Program Studi Ilmu Keperawatan Sekolah Tinggi Ilmu Kesehatan Indonesia Maju \\ Email :bambangadyputro99@gmail.com ${ }^{1}$, :Shifajars@ gmai.com ${ }^{2}$
}

\begin{abstract}
Abstrak
Pendahuluan: dalam penentuan kebutuhan dan prognosis kematian pasien diperlukan skoring kematian di Intensive care unit (ICU). Tujuan: Penelitian ini bertujuan untuk mengetahui hubungan skoring Acute Physiology And Chronic Health Evaluation (APACHE II) terhadap angka kematian pada pasien gagal nafas di Ruang ICU Rumah Sakit PMI Bogor Tahun 2019. Metode: rancangan dalam penelitian ini adalah cross sectional. Jumlah sampel yaitu 56 pasien gagal nafas. Intrumen menggunakan lembar cheklist apache dan uji statistik menggunakan uji Chi Square. Hasil:Ada hubungan skoring APACHE II terhadap angka kematian pasien gagal nafas di Ruang ICU Rumah Sakit PMI Bogor dengan Pvalue 0,02 dan OR 4,63. Kesimpulan:Ada hubungan skoring APACHE II terhadap angka kematian pasien gagal nafas. Diharapkan perawat membuat integrasi ICU dengan perhitungan APACHE II di ruang ICU.
\end{abstract}

Kata kunci: APACHE II, angka kematian, gagal nafas

\begin{abstract}
Introduction: The use of a score system for prediction of patient deaths in the Intensive Care Unit (ICU) is needed in determining ICU needs and prognosis. Objective: This study used a cross sectional design. The number of samples is 56 patients with respiratory failure. Method: Research instruments using Apache II observation sheets and statistical tests using the Chi Square test. Results: The results showed that there was a correlation between APACHE II scoring and mortality in patients with respiratory failure in ICU Room, Bogor PMI Hospital with a P value of 0.02 and OR 4.63. Conclusion: there was a correlation between APACHE II scoring and mortality in patients Research suggestions are expected that nurses can carry out strategies to manage the need to make a checklist for calculating APACHE II scores integrated in ICU.
\end{abstract}

Keywords: APACHEII, death rate, respiratory failure

\section{Pendahuluan}

Suatu bentuk kegagalan dalam difusi gas oksigen dan karbondioksida pada sistem pernafasan merupakan bentuk dari kegagalan pernafasan, gagal nafas masih menjadi angka kejadian yang terus terjadi meskipun zaman sudah semakin maju dan intervensi sudah cukup berkembang. ${ }^{1}$

Pada 2015, World Health Organization (WHO) melaporkan bahwa gagalnapas merupakan penyebab dunia yang terbesar tunggal kematian pad a dewasa usia > 40 tahun sekitar 922.000 kematian per tahun. Kematian pada dewasa usia> 40 tahun sekitar 922.000 kematian per tahun. Data dari Centers for Disease Control and Prevention (CDC) menunjukkan bahwa di AS selama tahun 2013 terdapat 56.979 kematian yang berhubungan dengan pneumonia dan 149.205 kematian akibat penyakit saluran napas bawah. $^{2}$

RISKESDAS 2013 menyatakan prevalensi kematian akibat gagal nafas di Indonesia mencapai 20,5\%. Beberapa penyebab gagal napas dapat berupa $\mathrm{Tb}$ paru dan Bronhopnemoni. ${ }^{3}$ Berdasarkan riset kesehatan dasar tahun 2013 prevalensi Tb paru dan Bronhopnemoni di Provinsi Jawa 
Barat masing-masing adalah $3,6 \%$ dan $2,4 \%{ }^{3}$

Menurut hasil penelitian Manik dalam Yanda, di rumah sakit haji medan tahun 2010-2012 terdapat 132 penderita ppok dan14 diantaranya meninggal dunia. ${ }^{4}$ Kegagalan pernapasan akut sering dikaitkan dengan infeksi paru, infeksi yang paling umum adalah pneumonia. Angka kematian di ICU perlu diprediksi dengan baik hal ini dikarenakan dapat menjadi bantuan dalam hal pemantauan informasi pada pasien itu sendiri yang ada hubungannya dengan kondisi dan korelasi antara penyakit pasien yang terjadi. Dalam prediksi kematian bukan prediksi kinerja, evaluasi yang diberikan dan difokuskan kepada pasien yang mengalami disfungsi organ sangat membantu dalam hal prognosis penyakit pasien dan penanganan yang cepat dan tepat terhadap apsien sehingga menurunkan angka disfungsi organ yang lain kepada pasien, dimana kegagalan organ ada hubungan dengan meningkatnya mortalitas pasien ICU. ${ }^{5}$

Skoring ICU terdapat beberapa penialaian seperti Sequential Organ Failure Assesment (SOFA) dan APACH serta sejumlah skor yang lainnya untuk digunakan mengetahui mortalitas pasien dan juga untuk menilai prognosis pasien. Skoring digunakan untuk membuat perkiraan terkait perkembangan kesehatan pasien yang sedang dirawat di ICU baik dalam kondisi sembuh ataupun dalam kondisi pasien meninggal. Skoring yang memungkinkan untuk dilakukan di ICU adalah APACHE II dan APACHE III serta SAPS (Simplified Acute Physiological
Score II) serta (Mortality Probability Model II). ${ }^{6}$

Skoring APACHE II juga berfungsi untuk meliaht perkembangan pasien terkait kematian, tingkat keparahan suatu penyakit dan berapa lama perawatan dilakukan kepada pasien. Sehat karena itu maka skoring APACHE II sangat diperlukan untuk ruangan kritis seperti ICU. Hal ini akan membuat perawat dan dokter mudah dalam menentukan prognosa diagnosa terhadap pasien yang sedang dirawat pada ruangna ICU. ${ }^{2}$

Kanus dalam penelitiannya yang di lakukan di Jerman menyatakan bahwa APACHE II, III dan SAPS II memiliki tingkat akurasi yang baik dalam prediksi mortalitas pasien. ${ }^{9}$ Knaus dalam penelitian menyatakan bahwa APACHE II memiliki sensitivitas dan spesifitas $38 \%$ dan $99 \%$. Dalam hal prediksi dalam merawat pasien yang di rawat di ICU. ${ }^{7}$

Berdasarkan hasil studi pendahuluan dengan melakukan pengamatan pada data rekam medik di ruang ICU Rumah sakit PMI Bogor diperoleh angka kematian tahun 2018 sebanyak 411 dari 1.114 (36,9\%) pasien yang masuk perawatan ICU. Sedangkan angka kematian tahun sebelumnya di tahun 2017 ada sebanyak 325 dari $1076(30,2 \%)$ pasien pasien yang masuk perawatan ICU. Hal ini menunjukan ada peningkatan $6,7 \%$ angka kematian di tahun 2018 dibandingkan dengan angka kematian pasien di tahun 2017 di Rumah sakit PMI Bogor.

Selama periode 3 bulan terakhir tahun 2019 juga diperoleh angka kematian pasien yang mengalami peningkatan setiap bulannya. Angka kematian pasien ICU bulan 
Januari 2019 sebanyak 31 dari 84 pasien (36,9\%), bulan Februari 2019 sebanyak 35 dari 83 pasien $(42,2 \%)$ dan meningkat kembali pada bulan Maret 2019 sebanyak 37 dari 82 pasien $(45,1 \%)$. Fenomena inilah yang menjadikan penulis perlu dilakukan penelitian kembali tentang skoring APACHE II terhadap angka kematian pada pasien gagal nafas di Ruang ICU.

Tujuan penelitian ini adalah untuk mengetahui hubungan skoring APACHE II terhadap angka kematian pada pasien gagal nafas di Ruang ICU Rumah Sakit PMI Bogor Tahun 2019.

\section{Metode}

Dalam penelitian ini peneliti menggunakan metode analitik dimana hal ini berfungsi untuk melihat korelasi antar variabel yang dihubungkan dengan fenomena yang terjadi. $^{10}$

Suatu kumpulan responden yang memiliki karakteristik yang sama untuk dijadikan sampel penelitian adalah populasi. $^{12}$ Populasi dalam penelitan ini adalah pasien gagal nafas di Ruang ICU Rumah Sakit PMI Bogor periode Januari Maret 2019 sebanyak 103 orang. Jumlah sampel adalah sebesar 56 responden. Pengambilan sampel menggunakan purposive sampling. Sebelum melakukan penelitian kepada responden terpilih, peneliti terlebih dahulu melakukan uji etical clearance yang sudah disahkan oleh Sekolah Tinggi Ilmu Kesehatan Indonesia Maju Jakarta pada tanggal 16 Juli 2019 dengan nomer uji etik:

2325/Sket/KaDept/RE/STIKIM/VII/2019.

Penelitian ini dilaksanakan di Rumah Sakit PMI Bogor, Jawa Barat. Pengambilan data dilaksanakan pada bulan Februari 2019 dan penelitian dimulai sejak Mei 2019. ${ }^{13}$ Analisa univariat digunakan untuk mendeskripsikan variabel yang diteliti dengan cara membuat tabel distribusi frekuensi, dan data disajikan dalam bentuk persentase. $^{13}$

\section{Hasil}

Tabel 1.

Distribusi Frekuensi Karakteristik Responden

\begin{tabular}{lcc}
\hline \multicolumn{1}{c}{ Karakteristik } & Jumlah & \% \\
\hline Jenis kelamin & & 68 \\
\hline Laki - laki & 38 & 32 \\
\hline Perempuan & 18 & \\
\hline Usia & & 27 \\
\hline $45-59$ tahun & 15 & 64 \\
\hline $60-75$ tahun & 36 & 9 \\
\hline $76-90$ tahun & 5 & 27 \\
\hline Pendidikan & & 70 \\
\hline SMP & 15 & 4 \\
\hline SMA & 39 & \\
\hline Perguruan Tinggi & 2 & \\
\hline Pekerjaan & & \\
\hline
\end{tabular}




\begin{tabular}{lcc}
\hline Tidak bekerja/IRT & 47 & 84 \\
\hline Bekerja & 9 & 16 \\
\hline
\end{tabular}

Sumber: Data Primer 2019

Hasil analisis skoring APACHE II dengan angka kematian pasien gagal nafas di Ruang ICU Rumah Sakit PMI Bogor, diketahui dari 37 responden umumnya memiliki skoring APACHE II tinggi, sebanyak 27 responden $(73 \%)$ diantaranya mengalami kematian yang tinggi.

Dari 56 responden, mayoritas pasien gagal nafas berjenis kelamin laki-laki sebanyak 38 orang (68\%), berusia $60-75$ tahun sebanyak 36 orang (64\%), berpendidikan SMA. Sebanyak 39 orang (70\%) dan sebagian besar pasien gagal nafas tidak bekerja atau ibu rumah tangga ada sebanyak 47 orang (84\%).

Tabel 2

Distribusi frekuensi Skoring Apache II dan Angka kematianpasien gagal nafas

\begin{tabular}{lcc}
\hline \multicolumn{1}{c}{ Variable } & Jumlah \% & Skoring Apache II \\
\hline Rendah & 19 & 34 \\
\hline Tinggi & 37 & 66 \\
\hline Angka kematian & & \\
\hline Rendah & 22 & 39 \\
\hline Tinggi & 34 & 61 \\
\hline
\end{tabular}

Sumber : Data Primer 2019

Hasil penelitian distribusi frekuensi skoring APACHE II pasien gagal nafas di Rumah Sakit PMI Bogor, didapatkan bahwa sebagian besar pasien gagal nafas mendapatkan skoring APACHE II tinggi sebanyak 37 orang (66\%). Angka kematian pasien gagal nafas di ruang ICU Rumah Sakit PMI Bogor, didapatkan bahwa pasien gagal nafas lebih banyak yang mengalami kematian yang tinggi sebanyak 34 orang (61\%) di Rumah Sakit PMI Bogor.

Hasil uji statistik chi square hubungan skoring APACHE II dengan angka kematian pasien gagal nafas diperoleh nilai $\mathrm{p}=0,02$ artinya $p$ value $\leq$ alpha $(0,05)$, sehingga dapat disimpulkan hipotesis alternatif (Ha) diterima atau ada hubungan skoring APACHE II terhadap angka kematian pada pasien gagal nafas di Ruang ICU Rumah Sakit PMI Bogor Tahun 2019. Berdasarkan hasil odd ratio (OR) didapatkan hasil bahwa skor APACHE II yang tinggi memiliki peluang 4,6 kali pasien gagal nafas mengalami kematain yang tinggi dibandingkan dengan skor APACHE II yang rendah. 


\section{Tabel 3}

Hubungan Antara Skoring Apache II denganAngka kematian Pada Pasien gagal nafas di Rumah Sakit PMI Bogor Tahun 2019

\begin{tabular}{|c|c|c|c|c|c|c|c|}
\hline \multirow{3}{*}{$\begin{array}{l}\text { Skoring } \\
\text { Apache II }\end{array}$} & \multicolumn{4}{|c|}{ Angka Kematian } & \multirow{3}{*}{ Total } & \multirow{3}{*}{ P-Value } & \multirow{3}{*}{$\begin{array}{c}\text { Odd Rasio }(95 \% \\
\text { CI })\end{array}$} \\
\hline & \multicolumn{2}{|c|}{ Rendah } & \multicolumn{2}{|c|}{ Tinggi } & & & \\
\hline & $\mathrm{n}$ & $\%$ & $\mathrm{n}$ & $\%$ & & & \\
\hline Rendah & 12 & 63 & 7 & 37 & 19 & \multirow{3}{*}{0,02} & \multirow{3}{*}{$\begin{array}{c}4,63 \\
(1,42-15,1)\end{array}$} \\
\hline Tinggi & 10 & 27 & 27 & 73 & 37 & & \\
\hline Jumlah & 22 & 39 & 34 & 61 & 56 & & \\
\hline
\end{tabular}

Sumber : Data Primer 2019

\section{Pembahasan}

\section{Gambaran Karakteristik Responden}

Hasil penelitian dan uji statistik univariat dinyatakan bahwa sebagian besar pasien gagal nafas berjenis kelamin laiklaki $(68 \%)$. Hal ini sejalan dengan penelitian Heny dyang meneliti skor APACHE II dan mortalitas di ICU RSUP Dr. Kariadi dengan hasil penelitian membuktikan bahwa pasien terbanyak yang meninggal dunia di ruang ICU adalah berjenis kelamin laki-laki. ${ }^{14}$

Peneitian yang dilakukan peneliti tidak sejalan dengan penelitian di Pakistan yang menyatakan bahwa perempuan lebih dominan daripada pria, penelitian yang dilakukan di Rumah Sakit Hasan Sadikin Bandung juga menyatakan bahwa pasien ICU yang sembuh dan keluar mayoritas adalah perempuan. Hal tersebut dimungkinkan pada tempat tersebut penyakit yang ditimbul pada pasien-pasien itu adalah gangguan obstetri. ${ }^{15}$

Rentannya laki-laki terhadap paparan ganguan kesehatan terutama penyakit gagal nafas dan faktor kejiwaan ini tidak hanya ada di Indonesia, menurut (WHO), negara-negara lain di Asia Tenggara juga memiliki kasus yang sama, yaitu ganguan kesehatan gagal nafas lebih banyak dialami oleh laki-laki dibandingkan wanita karena pasien memiliki riwayat penyakit Pneumonia dan kasus TB Paru. ${ }^{16}$

Menurut analisa penulis, sebagian besar pasien gagal nafas terjadi pada lakilaki karena riwayat kesehatan laki-laki cenderung memiliki kebiasaan merokok aktif. Laki-laki juga memiliki pekerjaan yang berat dan beresiko yang menyebabkan gangguan pernafasan. Pasien gagal nafas yang berjenis kelamin laik-laki di ruang ICU lebih tinggi angka kematiannya di bandingkan dengan wanita, disebabkan pasien laki-laki di ruang ICU sebelumnyya juga memiliki pola hidup yang tidak teratur.

Berdasarkan hasil analisis univariat menunjukan bahwa distribusi frekuensi lebih banyak responden yang memiliki usia 60 - 75 tahun sebanyak 64\%. Usia 60-75 adalah rentang yang paling banyak di ruangan ICU dengan kondisi telah meninggal dan usia 45-59 dengan presentase $27 \%$ dan presentase $9 \%$ pada usia $76-90$ tahun.

Kim menguatkan penelitian ini dengan hasil penelitian menyatakan bahwa usia 50-69 tahun adalah usia dimana pasien banyak kaluar dari ICU tetapi Kim menyatakan hasil usia dibawah 44 tahun yang banyak atau dominan keluar dari ICU 
dalam kondisi meninggal dunia ${ }^{17}$. Hasil penelitian menunjukan ada keterkaitan antara usia seseorang dengan perilaku hidup sehat, semakin meningkat usia seseorang maka akan mengalami penurunan sistem imun. Ketika seseorang berada pada usia lanjut maka tingkat kepuasan dalam hal pelayanan lebih mudah dalam menerima dibandingkan usia dibawahnya, dampak dari hal tersebut adalah penerimaan pasien lanjut usia terhadap dokter dan perawat.

Menurut asumsi penulis, umur yang semakin bertambah maka berkaitan dengan keluarnya pasien di ICU, outcome pasien juga ditentukan dengan usia dan status kesehatan pasien sebelumnya. Penyakit mudah menyerang pada individu yang sistem imunnya menurun, sehingga pada usia yang lebih tua akan sangat rentan terjadinya ganguan kesehatan. Responden dengan usia yang lebih tua memiliki tuntutan dan harapan tinggi terhadap pelayanan yang dilakukan di rumah sakit sehingga tingkat kecepatan pelayanan menjadi hal penting untuk kepuasan pasien.

Berdasarkan hasil analisis univariat menunjukan bahwa distribusi frekuensi lebih banyak responden yang memiliki pendidikan SLTA sebanyak 70\%. Hal ini sejalan dengan penelitian Heny yang meneliti tentang APACHE II dan tingkat kematian di ICU RSUP Dr. Kariadi dengan hasil penelitian membuktikan bahwa pasien terbanyak yang meninggal dunia di ruang ICU adalah berpendidikan SMA. ${ }^{15}$

Pendidikan seseorang merupakan gambaran tingkat pengetahuan pasien, maka oleh karena itu pendidikan adalah juga faktor yang ikut berpengaruh terhadap harapan pasien dalam pelayanan yang diberikan, dimana ketika penidikan pasien tinggi maka tingkat harapan maka semakin meningkat sehingga kualitas dari layanan harus lebih ditingkatkan. $^{18}$

Menurut asumsi penulis, Semakin tinggi tingkat pendidikan seseorang, maka semakin besar kemauan pasien untuk sembuh dari penyakitnya. Sebagian besar keluarga pasien ruang ICU berpendidikan SLTA, karena kesehatan akan semakin mudah dimengerti oleh seseorang yang berpendidikan tinggi, tuntuntan dan harapanpun akan semakin tinggi pula dimana hal ini menjadi bertolak belakang dengan pendidikan yang rendah.

Berdasarkan hasil analisis univariat menunjukan bahwa distribusi frekuensi lebih banyak responden yang tidak memiliki pekerjaan sebanyak 84\%. Hal ini sejalan dengan penelitian Heny yang meneliti tentang APACHE II dan angka kematian pasien di ICU RSUP Dr. Kariadi dengan hasil penelitian membuktikan bahwa pasien terbanyak yang meninggal dunia di ruang ICU adalah berprofesi tidak bekerja (pensiun). ${ }^{15}$

Hasil penelitian menyebutkan bahwa pekerjaan pasien lebih banyak berprofesi tidak bekerja, karena pekerjaan mempengaruhi kemampuan perawatan pasien ICU oleh keluarga yang memiliki harapan yang tinggi terhadap kesembuhan dibandingkan dengan yang tidak bekerja. Pekerjaan akan ikut berpengaruh terhadap tingkat rasa puas seorang pasien dikarenakan keseimbangan akan dituntut oleh pasien dengan apa yang telah ia bayar. $^{18}$

Menurut asumsi penulis, sebagian besar pasien rawat inap berprofesi tidak 
bekerja, karena responden yang tidak bekerja pada umumnya memiliki kesejahtraan yang kurang baik dan sepenuhnya ditanggung oleh keluarga atau asuransi sehingga kurang mampu membiayai biaya rumah sakit yang mahal dan sebagian keluarga responden juga berpendapat biaya perawatan ICU lebih memanfaatkan jaminan dari kantor atau asuransinnya.di bandingkan dengan responden dengan pekerjaan lainnya.

\section{Gambaran Skoring Apache II}

Hasil distribusi frekuensi skoring APACHE II pasien gagal nafas di Rumah Sakit PMI Bogor, didapatkan bahwa sebagian besar pasien gagal nafas mendapatkan skoring APACHE II tinggi sebanyak 66\%. Analisis stratidikasi dilakukan karena adanya perbedaan karakteristik dari kedua kelompok dengan nilai APS $<6,78+3,2$ dan $16,42+9,6$ $(\mathrm{p}=0,000)$, jarang disertai komorbid berat dengan skor komorbid lebih rendah dan rerata umur lebih rendah 39+1,3 dibandingkan 50+1,7 ( $\mathrm{p}=0,000)$. Perbedaan rerata skor APACHE II karena tindakan bedah elektif sehingga rerata umur, APS dan skor penyakit kronik lebih rendah daripada kasus nonbedah. ${ }^{19}$

Hasil penelitian ini juga diperkuat oleh penelitian Heny (2014) tentang skore angka kematian pasien dan skor APACHE II di ICU RSUP Dr. Kariadi dengan hasil penelitian membuktikan cukup baik dalam hal prediksi kematian pasien yang dirawat di ruangan ICU. Hasil penelitian Diah (2015) tentang Sistem Skor APACHE II Sebagai Prediksi Mortalitas Pasien yang dirawat di ICU menyatakan bahwa skor 26,05 dimiliki oleh pasien peunomonia yang dirawat di ICU, perhimpunan dokter paru Indonesia menyatakan bahwa gangguan multi organ yang berat dan gangguan fungsi tubuh adalah indikasi untuk rawat IPI. ${ }^{15}$

Menurut asumsi penulis, prediksi dalam hal pasien yang dirawat di ICU menjadi sesuatu yang baik dilakukan dengan skoring APACHE II karna untuk melihat status dan prognosis penyakit pasien dalam masa perawatan yang dilkaukan di rumah sakit, hal ini juga membantuk perawat dan dokter dalam menangani pasien untuk memprediksi pasien pulang atau keluar baik dalam keadaan sembuh atau meninggal dunia.

\section{Gambaran Angka Kematian}

Distribusi frekuensi angka kematian pasien gagal nafas di ruang ICU Rumah Sakit PMI Bogor, didapatkan bahwa pasien gagal nafaslebih banyak yang mengalami kematian yang tinggi sebanyak 61\%. Alasan masuk ICU pada pasien non bedah di RS PMI Bogor pada penelitian ini adalah pada kasus gagal nafas. Penyebab angka kematian pasien rawat inap paling tinggi adalah kasus Pneumonia (12,6\%$15,9 \%)$ dan kasus TB Paru (8,8\%-11,0\%).

Hasil penelitian ini sejalan dengan penelitian Diah tentang (Apache) II Sebagai Prediksi Mortalitas Pasien Rawat Instalasi Perawatan Intensif. Hasil penelitian menunjukkan bahwa sekitar 27,2\% dengan 64 orang dinyatakan keluar dari rumah sakit dalam keadaan meninggal dunia, sisanya yaitu sekitar $72,8 \%$ atau sebanyak 171 orang pasien yang bertahan hidup selain itu terdapat cukup bermakna perbedaan antara yang hidup dengan yang meninggal, kegagalan terapi yang dilakukan mungkin saja terjadi, perawatan IPI yang cukup mahal 
menjadi bahan untuk dipertimbangkan oleh dokter dan keluarga pasien sehingga telah datang dengan kondisi yang sudah memburuk. ${ }^{20}$

Menurut asumsi penulis, bahwa jenis atau kasus penyakit serta adanya penyakit penyerta atau komorbid yang memperberat tingkat keparahan penyakit bisa menjadi penilaian outcome pasien ICU. Prediksi dalam skoring seperti APACHE II sangat penting untuk dilakukan hal ini dikarenakan salah satunya adalah efektifitas cost yang dikeluarkan terutama untuk keluarga pasien, selain itu juga dapat dilihat prognosis pasien secara keseluruhan atas pengobatan dan perawatan yang telah dilakukan selama di ruangan ICU di rumah sakit, dan hal ini menjadi cukup penting untuk meninjau tingkat mortalitas pasien yang dirawat di ICU.

\section{Hubungan Skoring APACHE II Terhadap Angka Kematian}

Analisis hubungan skoring APACHE II dengan angka kematian pasien gagal nafas di Ruang ICU Rumah Sakit PMI Bogor, diketahui dari 37 responden umumnya memiliki skoring APACHE II tinggi, sebanyak $73 \%$ responden diantaranya mengalami kematian yang tinggi, 27\% responden mengalami kematian yang rendah. Hasil uji statistik chi square hubungan skoring APACHE II terhadap angka kematian pasien gagal nafas diperoleh nilai $\mathrm{p}=0,02$ artinya ada hubungan skoring APACHE II terhadap angka kematian pada pasien gagal nafas di Ruang ICU Rumah Sakit PMI Bogor Tahun 2019. Skor APACHE II yang tinggi memiliki peluang 4,6 kali pasien gagal nafas mengalami kematain yang tinggi dibandingkan dengan skor APACHE II yang rendah.

Peranan penting yang dimiliki ruang ICU adalah salah satu faktor yang menentukan tingkat kesembuhan pasien, dalam hal prediksi kapan pasien keluar adalah bagian penting yang dapat dilaksanakan di ruangan ICU, skoring APACHE II daapt digunakan untuk menentukan skore pasien tersebut, sistem skoring ini cukup efektif dalam hal prediksi pasien keluar baik dalam keadaan sembuh ataupun meninggal dunia. ${ }^{20}$

Hasil penelitian ini sejalan dengan penelitian Heny yang meniliti korelasi antara APACHE II dan angka kemarian di RSUP Dr. Kariadi Semarang rata-rata skor APACHE II didapatkan 20,24+8,097. Rerata APACHE II score pasien yang keluar ICU lebih tinggi pasien dalam kondisi meninggal dunia dibandingkan pasien hidup $(30,11 \pm 5,08$ vs $16,49 \pm 5,42, p=0,01)$. Sebesar $27,6 \%$ kematian yang terjadi pada rumah sakit Dr. Kariadi. Tiga besar diagnosis akhir pasien sebelum kematian adalah syok septik $10(37 \%)$, acute myocard infarct $3(11,1 \%)$, dan chronic heart failure $3(11,1 \%)$. Kesimpulan: Terdapat korelasi yang bermakna antara APACHE II score dengan angka kematian $(p=0,001)$. Ketika skor APACHE II cukup tinggi maka kondisi pasien meninggal ketika keluar dari ICU juga semakin tinggi (r:+0,705). ${ }^{15}$

Menurut asumsi penulis, kebutuhan akan skoring untuk memprediksi kematian atau prognosis pasien yang dirawat di ICU menjadi sebuah kebutuhan yang penting selain memberikan kemudahan dalam pelayanan dan intervensi yang akan dilakukan selanjutnya, cost juga akan dapat 
ditekan terutama untuk keluarga pasien yang dirawat di ICU, skor prediksi ini akan dijadikan patokan oleh perawatdan dokter dalam hal tindakan yang akan dilakukan selanjutnya terkait dengan kondisi pasien saat itu, selain itu tingkat efisiensi, mutu dan kualitas pelayananpun akan terjadi peningkatan.

\section{Kesimpulan}

Kesimpulan dalam penelitian ini adalah sebagian besar pasien gagal nafas berjenis kelamin laki-laki, berusia 60 -75 tahun, berpendidikan SMA dan tidak bekerja atau berprofesi sebagai ibu rumah tangga. Skoring APACHE II pada pasien gagal nafas di Rumah Sakit PMI Bogor tergolong tinggi. Sebagian besar pasien gagal nafas lebih banyak yang mengalami kematian yang tinggi. Ada hubungan skoring APACHE II terhadap angka kematian pada pasien gagal nafas di Ruang ICU Rumah Sakit PMI Bogor. APACHE II baik untuk diimplementasikan dalam memaksimalkan outcomedi ruang ICU.

\section{Daftar Pustaka}

1. Surjanto E, Sutanto YS, Reviono, Prasetyo Y, Suradi. The Relationship Between Underlying Disease of Respiratory Failure with The Treatment's Outcome on Hospitalized Patients in Dr. Moewardi Hospital Surakarta 2013. Department of Pulmonology and Respirology Faculty of Medicine Sebelas Maret University Surakarta; 2013.

2. Sogaard M, Madsen M, Løkke A, Hilberg O, Sørensen HT, Thomsen RW. Incidence and outcomes of patients hospitalized with COPD exacerbation with and without pneumonia. International journal of COPD;2016.

3. Kemenkes RI. Riset Kesehatan Dasar; RISKESDAS. Jakarta: Balitbang Kemenkes RI; 2015.

4. Yanda S. Gambaran Analisa Gas Darah pada Distres Pernapasan. Sari Pediatri, Vol. 4, No. 3, pp:135-140; 2012.

5. Zimmerman JE, Kramer AA, Mc Neir DS, Malila FM. Acute physiology and chronic health evaluation (APACHE) IV ICU length of stay benchmarks for today's critically ill patients. Chest;128:297S;2015

6. Chiavone PA, Sens YA. Evaluation of APACHI II system among intensive care patients at a teaching hospital. Sao Paulo Med J; 121:53-7.2016.

7. Knaus WA, Draper EA, Wagner DP, Zimmerman JE. APACHE II: a severity of disease classification system. Crit Care Med;13(10):818-29; 2016.

8. Nur Hajriya Brahmi. Validitas Skor Apache II, MSofa, dan SAPS 3 terhadap Mortalitas Pasien Non Bedah di perawatan Intensif dewasa RSUP $\mathrm{dr}$ Kariadi Semarang. Jurnal Volume VIII, Nomor 3; 2016

9. Erbes R, Oettel K, Raffenberg M, Mauch H, Schmidtloanas M, Lode H, Characteristic and outcome of patients with active pulmonary tuberculama rawatis requiring mechanical ventilation. Eur Respir J;27:12238;2016.

10. Notoatmodjo, Soekidjo. Metodologi Penelitian Kesehatan. Jakarta: Rineka Cipta; 2012. 
11. Sugiyono. Metode Penelitian Kuantitatif, Kualitatif dan R\&D. Bandung: ALFABETA; 2012.

12. Sugiyono. Metode Penelitian Administratif. Bandung: Alfabeta; 2011.

13. Arikunto, Suharsimi. Prosedur Penelitian Suatu Pendekatan Praktik. Jakarta: Rineka Cipta; 2013

14. Heny.Hubungan Apache II Score dengan angka kematian pasien di ICU RSUP Dr. Kariadi. Skripsi;2015.

15. Heni, Armiati. Hubungan APACHE II score dengan angka kematian pasien di ICU RSUP Dr. Kariadi Semarang pada periode Januari-Mei 2013. Skripsi; 2013

16. Markgraf R, Deutschinoff G, Pientka L, Scholten T. Comparison of acute physiology and chronic health evaluations II and III and simplified acute physiology score II: a prospective cohort study evaluating these methods to predict outcome in a German interdisciplinary intensive care unit. Crit Care Med;28(1):26-33;2013.

17. Kim H,Lee H, Shon YJ, Paik H, Park HP. 2014. Validation of the APACHE IV model and its comparison with the APACHE II, SAPS 3, and Korean SAPS 3 models for the prediction of hospital mortality in a Korean surgical intensive care unit. Korean J Anesthesiol 2014; August $\quad 67(2)$ : 115-122. DOI:10.4097/kjae.2014.67.2.115;2014.

18. Qiao Q, Lu G, Li M, Shen Y, Xu D. Prediction of outcome in critically ill elderly patients using APACHE II and SOFA scores. The Journal of International Medical Research; 40:1114-1121;2014

19. Sedlon P, Kamenik L, Skvaril J, Maly M, Taborsky M, Zavoral M. Comparison of the accuracy and correctness of mortality estimates for Intensive Care Unit patients in the internal clinics of the Czech Republic using APACHE II, APACHE IV, SAPS 3 and MPMoIII models. Med Glas ; 13(2):82-89;2016.

20. Diah. Sistem Skor Acute Physiology And Chronic Health Evaluation (Apache) II Sebagai Prediksi Mortalitas Pasien Rawat Instalasi Perawatan Intensi. Skripsi;2015 